\title{
Challenges of the Oral Cancer Burden in India
}

\author{
Ken Russell Coelho',2 \\ ${ }^{1}$ Department of Public Health and Primary Care, University of Cambridge, Forvie Site, Robinson Way, Cambridge CB2 0SR, UK \\ ${ }^{2}$ Pembroke College, Trumpington Street, Cambridge CB2 1RF, UK
}

Correspondence should be addressed to Ken Russell Coelho, ken.coelho.2010@pem.cam.ac.uk

Received 7 February 2012; Revised 8 June 2012; Accepted 21 June 2012

Academic Editor: Hermann Brenner

Copyright ( 2012 Ken Russell Coelho. This is an open access article distributed under the Creative Commons Attribution License, which permits unrestricted use, distribution, and reproduction in any medium, provided the original work is properly cited.

\begin{abstract}
Oral cancer ranks in the top three of all cancers in India, which accounts for over thirty per cent of all cancers reported in the country and oral cancer control is quickly becoming a global health priority. This paper provides a synopsis of the incidence of oral cancer in India by focusing on its measurement in cancer registries across the country. Based on the International Classification of Disease case definition adopted by the World Health Organisation, and the International Agency for Research on Cancer, this review systematically examines primary and secondary data where the incidence or prevalence of oral cancer is known to be directly reported. Variability in age-adjusted incidence with crude incidence is projected to increase by 2030. Challenges focus on measurement of disease incidence and disease-specific risk behavior, predominantly, alcohol, and tobacco use. Future research should be aimed at improving quality of data for early detection and prevention of oral cancer.
\end{abstract}

\section{High Burden of Oral Cancer in India}

Oral cancer is a major problem in the Indian subcontinent where it ranks among the top three types of cancer in the country [1]. Age-adjusted rates of oral cancer in India is high, that is, 20 per 100,000 population and accounts for over $30 \%$ of all cancers in the country [2]. The variation in incidence and pattern of the disease can be attributed to the combined effect of ageing of the population, as well as regional differences in the prevalence of disease-specific risk factors [3].

Oral cancer is of significant public health importance to India. Firstly, it is diagnosed at later stages which result in low treatment outcomes and considerable costs to the patients whom typically cannot afford this type of treatment [4]. Secondly, rural areas in middle- and low-income countries also have inadequate access to trained providers and limited health services. As a result, delay has also been largely associated with advanced stages of oral cancer [5]. Earlier detection of oral cancer offers the best chance for long term survival and has the potential to improve treatment outcomes and make healthcare affordable [6]. Thirdly, oral cancer affects those from the lower socioeconomic groups, that is, people from the lower socioeconomic strata of society due to a higher exposure to risk factors such as the use of tobacco [7]. Lastly, even though clinical diagnosis occurs via examination of the oral cavity and tongue which is accessible by current diagnostic tools, the majority of cases present to a healthcare facility at later stages of cancer subtypes, thereby reducing chances of survival due to delays in diagnosis [8].

Public health officials, private hospitals, and academic medical centres within India have recognised oral cancer as a grave problem. Efforts to increase the body of literature on the knowledge of the disease aetiology and regional distribution of risk factors have begun gaining momentum. Oral cancer will remain a major health problem and efforts towards early detection, and prevention will reduce this burden. In light of this, the objective of this paper is to review and summarise existing literature on the descriptive epidemiology of oral cancer in India, focusing on the incidence of disease in the country.

\section{Case Definition of Oral Cancer}

Due to the heterogeneity of pathologies presented in oral cavity tumour research, as well as the intraoral cavity evaluation with respect to the subsites such as the oropharynx, the case 


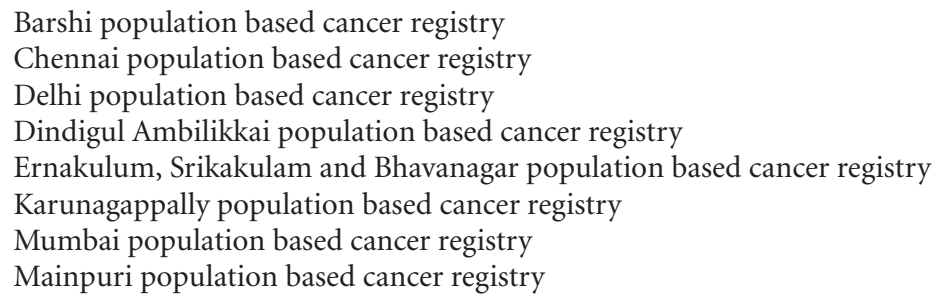

Box 1: List of cancer registries reporting incidence of oral cancer.

definition for oral cancer has been further complicated. Due to this failure to specify and define oral cancer in peerreviewed literature, meaningful comparisons for description and epidemiological purposes have proved to be a challenge. To minimise misclassification errors and for the purpose of this review, oral cancer is defined as the cancer of the lip, mouth, and tongue, to include the anatomic description of the oral cavity as reported in previous major populationbased research reports [9]. This case definition is adopted, and conforms to the definitions of oral cavity cancer by the International Classification of Diseases (ICD) Coding scheme, WHO case definitions and IARC. Based on these criteria, oral cavity cancer is the 8 th most frequent cancer in the world among males and 14th among females [6], the main risk factors being tobacco and alcohol use.

\section{Search Strategy}

A systematic search of the literature was accomplished using the Pubmed Database. Medical Subject headings and free text terms included the following.

(1) "oral cancer" OR "mouth cancer" OR "tongue cancer." The use of these terms generated a list of numerous MeSH entry terms which included subheadings of these main terms to include mouth neoplasms, oral neoplasms, cancer of the mouth, and head and neck cancers. All these variations of the term were added to the search, except head and neck cancers since, this did not meet the case definition criterion.

(2) "Epidemiology" OR "Descriptive Statistics" OR "Incidence" OR "Prevalence" OR "Longitudinal" OR "Cohort" OR "Case Control" OR "Cross sectional."

Free text terms included

\section{(3) India OR South Asia.}

All three search terms were stringed together to perform a targeted search with the following inclusion criteria.

(1) Studies where incidence or prevalence of oral cancer was measured.

(2) Population-based studies-Hospital-/Communitybased registries.
(3) Studies with standardised criteria for diagnosis of oral cancer.

(4) Studies published in the English language.

The search strategy included all published studies referencing the incidence and, if possible, prevalence of oral cancer in various regions of India. Even though at first it was thought it would be important to limit the search to include only the most recent up-to-date studies from the past ten years, it was later decided that it would be important to include all studies in the initial review due to a dearth of available peer-reviewed literature on the specified case definition. The search revealed few frequency studies to include the associated risk factors for the disease, such as use of alcohol and tobacco. Even though a few of these studies were selected in the analysis, for the purpose of this paper, it was decided not to focus solely on these studies due to the heterogeneity in the case definitions of oral cancer.

Only studies presenting primary research were included as part of this review. All studies were included if they measured incidence of oral cavity cancer in a standardised manner. A number of studies generated through the search, presented primary data from national and regional cancer registries in India and were included in this review. Additionally, for the purpose of representativeness, information was also retrieved from an online repository of cancer registration data available through IARC, the cancer incidence in five continents series (CI5), volumes I-IX, the Plus data collection, and the Globocan Project; all of which are cancer incidence and mortality projects conducted under the auspices of the WHO.

\section{Search Results}

Out of the initial 416 articles generated from the first search, the abstracts were reviewed for determining inclusion based on the established criteria. Once review was completed, 28 studies were selected as relevant to the search. However, after reviewing full texts of all articles, 11 studies were determined to be types of studies which only measure the prevalence of the associated risk factors such as smoking or alcohol use without a direct measure of the incidence or prevalence of oral cancer. These 11 studies were excluded.

of these articles were included as studies based on primary data where the incidence or prevalence of oral cancer as per case definitions was known to be directly reported. 
Following an in-depth full-text review of the 17 studies, additional articles with secondary data were obtained via the references checks. These articles were only used as reference articles; no data was included in the analysis. A majority of these studies, namely 11 were cross-sectional studies, 8 of which described data from national and regional cancer registries within the country (Box 1 and Table 1). In most cases, registry data was also utilised as baseline data on population characteristics. Three of the studies described data from population-based prospective cohort studies; one of the studies utilised a randomized control trial conducted using a population-based cancer registry, one of the studies utilised a mixed methods approach to include a combination of cross-sectional design, ten-year followup and an intervention study. Only one of the studies utilised a case-control method nested within a population-based cancer registry. No specific review articles were identified in the search.

\section{Summary of Findings}

Summary of the study designs and characteristics of all the studies included in this review is presented in Table 1. Data reported in these studies span the last thirty five years across a number of regions within India. A number of these studies utilised data from urban and rural cancer registries established at the national or regional level. Urban registries included Delhi, Mumbai and Chennai, and rural registries included Barshi, Dindigul, Mainpuri, Karunagapally, Ernakulum, Srikakulam, and Bhavanagar.

Various study designs were employed to obtain a sample reflective of the Indian population. Most of these studies were population-based cross-sectional studies utilising cancer registry data, with the exception of some studies. Gupta et al. [12] conducted a case-control study; however, this study was nested within a larger study utilising a rural based population registry. Sankaranarayanan et al. [22] utilised a communitybased cluster-randomised controlled trial where participants were randomised to either an intervention group or a control group to test the effect of a screening programme on the oral cancer incidence and mortality. Mehta et al. [15] utilised a mixed methods approach conducted in different phases. Malaowalla et al. [13], Gupta et al. [23], and Cancela et al. [9] conducted population-based prospective cohort studies to examine the incidence of oral cancer tracked prospectively over a period of time.

Since most of the studies included national and regional surveys of a population, a wide range of ages were included; however, Khandekar et al. [4] selected participants in an older age group ( $>51-60$ years) and Maudgal et al. [17] selected participants in a younger age group (range 3-21 years).

Summary of case definitions and comments on all studies included in this review is presented in Table 2. In India, cancer is not a notifiable disease. Hence, most of the studies utilised an active case finding approach to register incident cases of oral cancer. Sources of registration data included government hospitals, private health centres, nursing homes, shelters, nongovernmental organisations (NGOs), and community welfare centres. A number of survey methods were

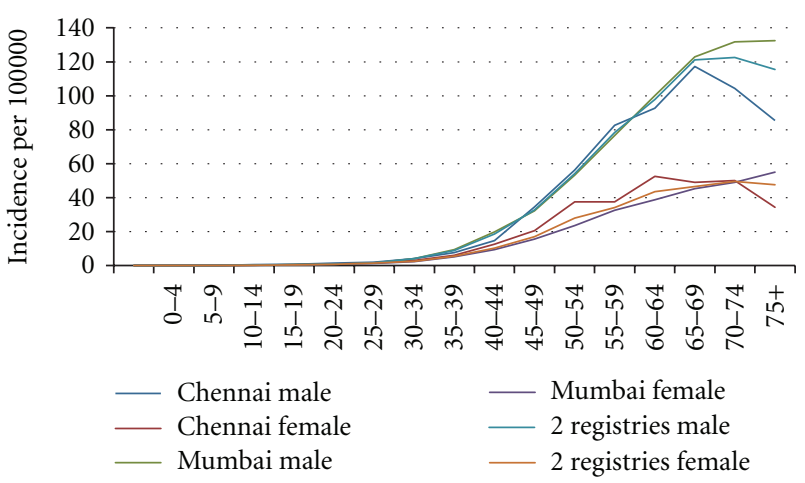

FIgURE 1: Age specific incidence rates lip, oral cavity cancer (includes: pharynx) 1983-2002. source: Ferlay et al. [26], IARC: 2010.

employed, including house-to-house recruitment, interviewing, and data abstraction from medical records. Standardised diagnostic criteria for the majority of the studies included the coding system devised by the WHO-ICD Classification for the definition of oral cancer. Mehta et al. [15] reported nonstandardised approach and utilised central papillary atrophy (CPA) of the tongue as a marker for oral lesions and precancer, determined by clinical examination conducted by the authors of the study.

\section{Measurement of Disease Incidence}

A majority of the studies reported the calculation of incidence rates as a measure of disease occurrence. Incidence is defined by the number of new cases of oral cancer, which occur in a defined population of disease-free individuals, over a specified period of time. The incidence rate of oral cancer is generally expressed for 100,000 population-over one year (or a range of years). IARC, in its series on the cancer Incidence in Five Continents, utilised incidence rates for a defined period [26]. Age- and sex-specific incidence rates are calculated to provide an estimate of the risk of oral cancer in defined groups in India. Figure 1 shows the age specific incidence rates for oral cancer between 1983 and 2002; by gender and location (based on 4 cancer registries) in India. An increasing trend based on age; however, lower incidence recorded amongst females as compared to males is indicative of gender differences in the lifestyle and behavioural patterns associated with incidence of oral cancer.

Additionally, incidence of oral cancer is age specific. Thus, for comparison of incidence rates in different areas or for the same area, over a period of time, it is necessary to adjust the rates for variations in the proportion of population in different age groups. The generally adopted procedure is that of direct standardisation, which applies the age- and sexspecific incidence rates of the area under consideration to world-standard population, to derive the number of cancer cases expected to occur in the standard population. Such age-standardised (or adjusted) incidence rates are useful in international or secular comparisons. 


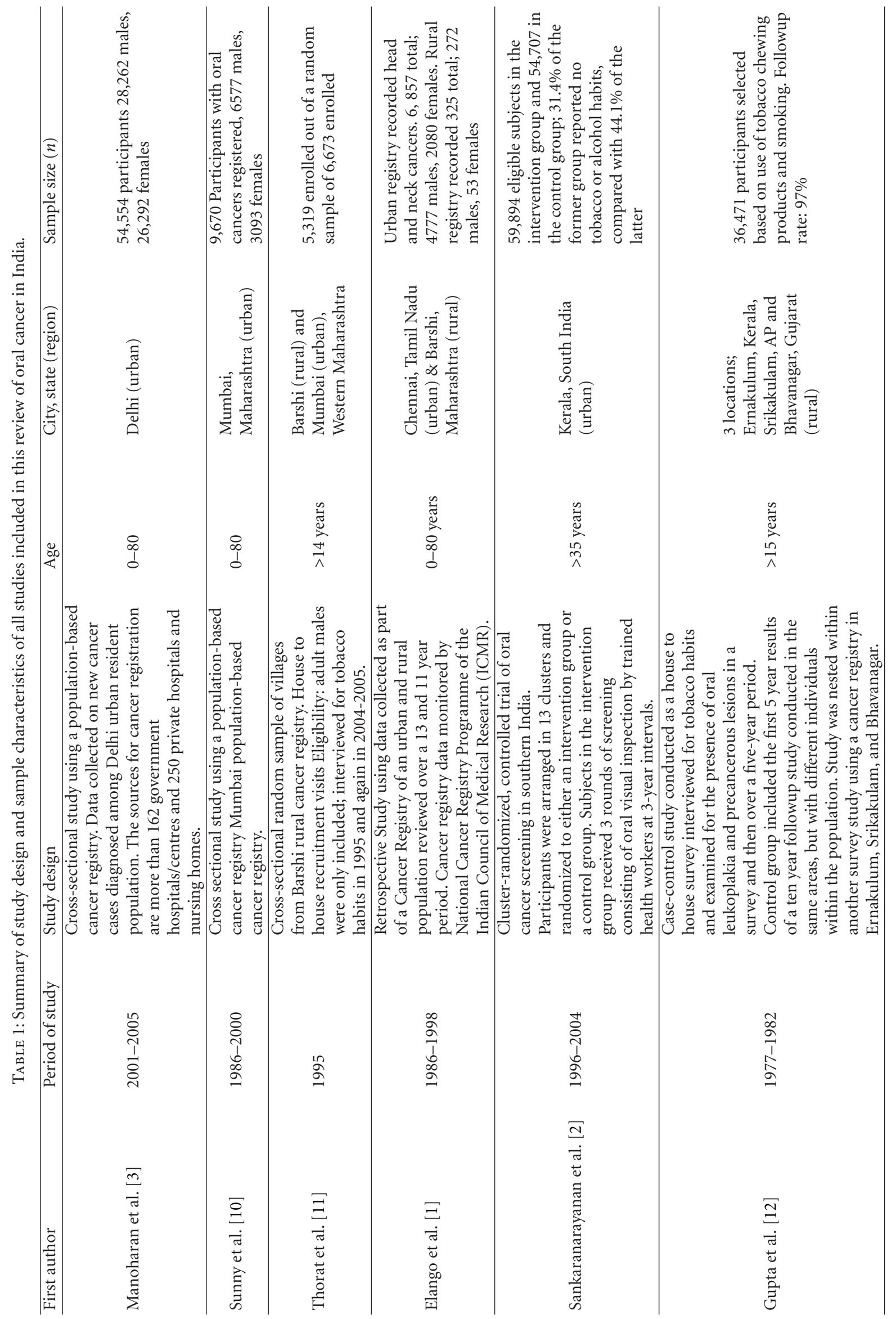




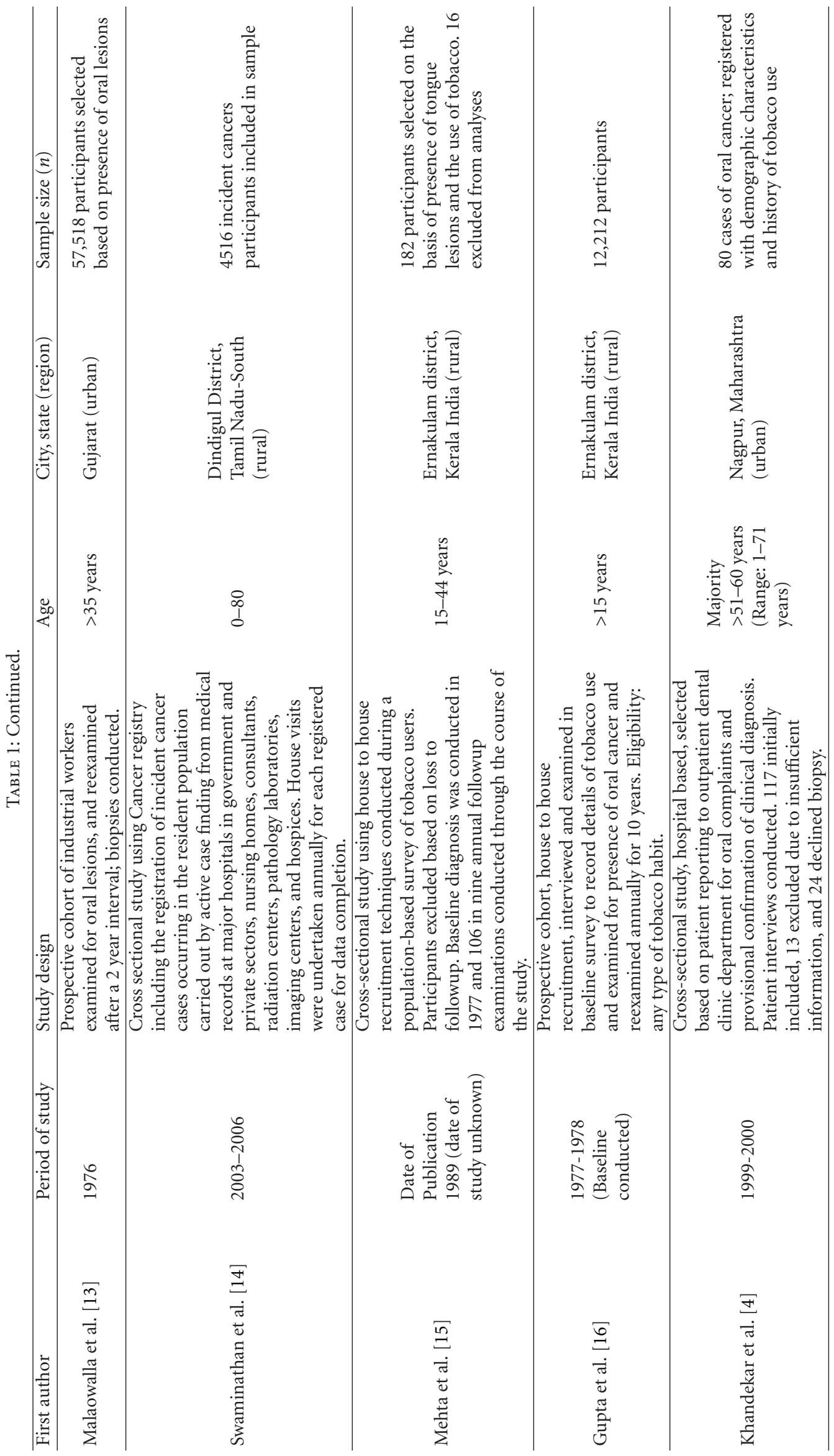




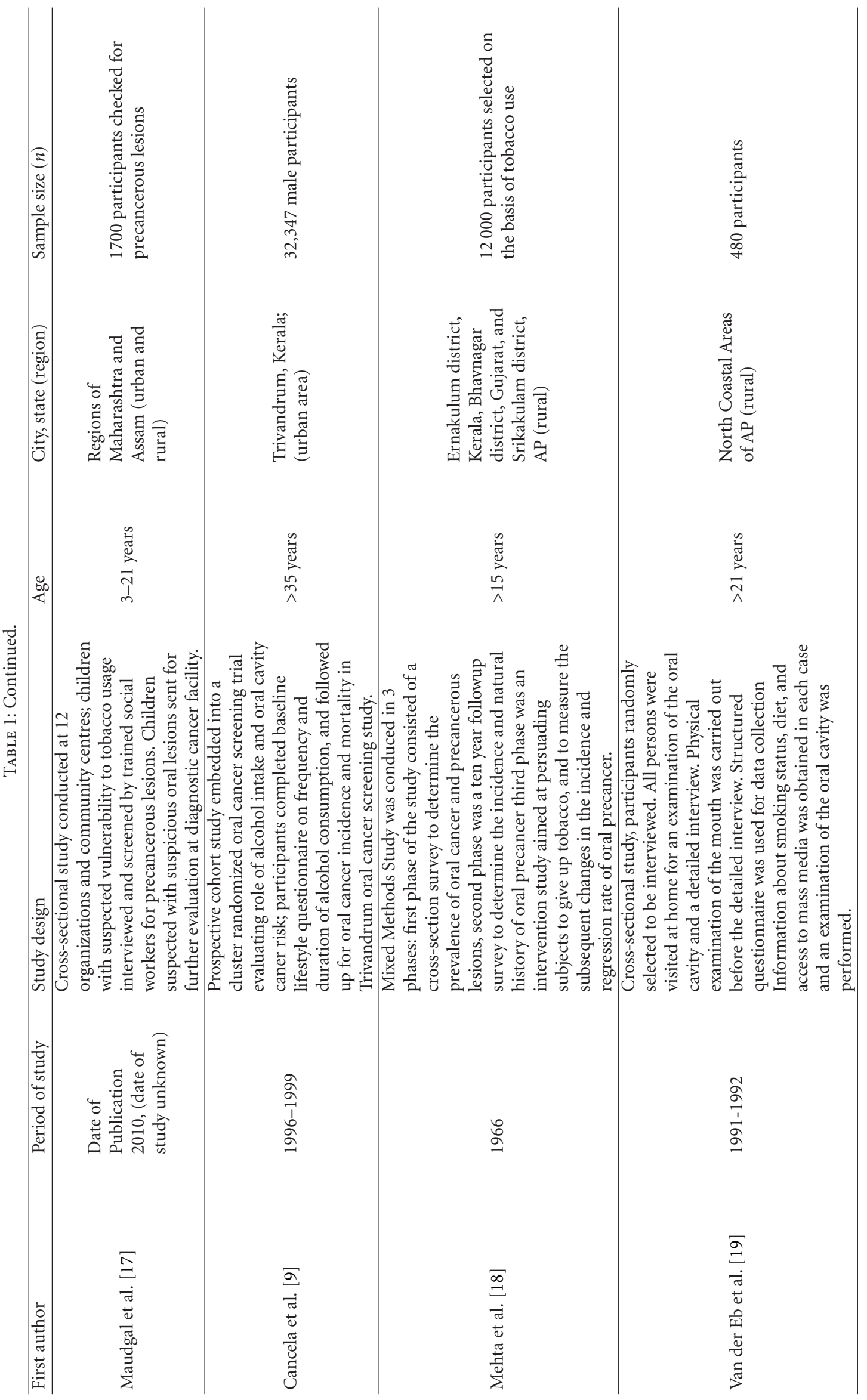




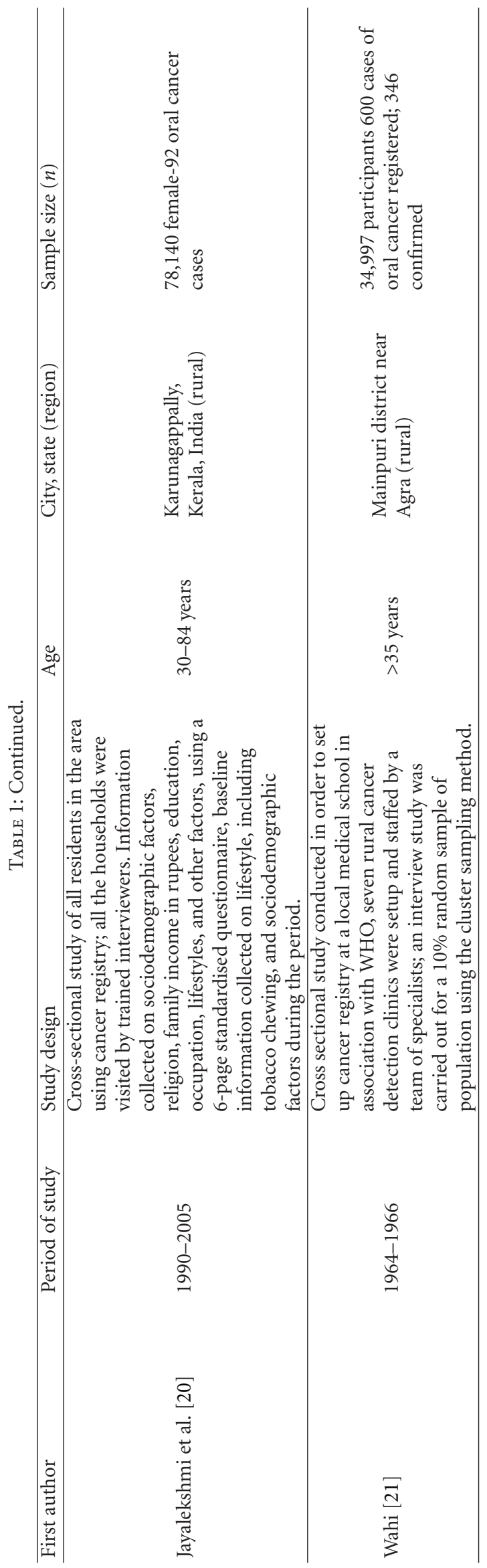




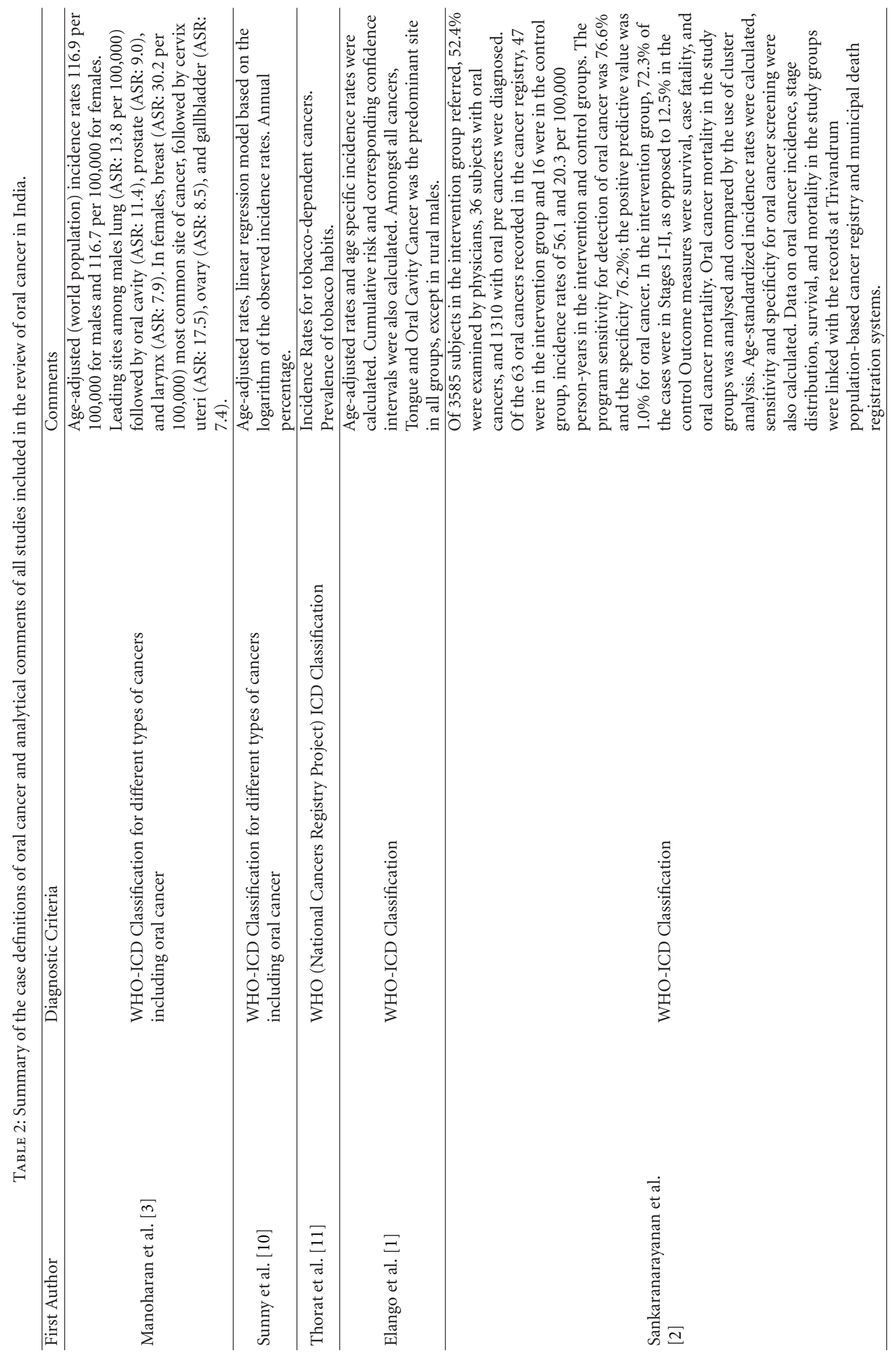




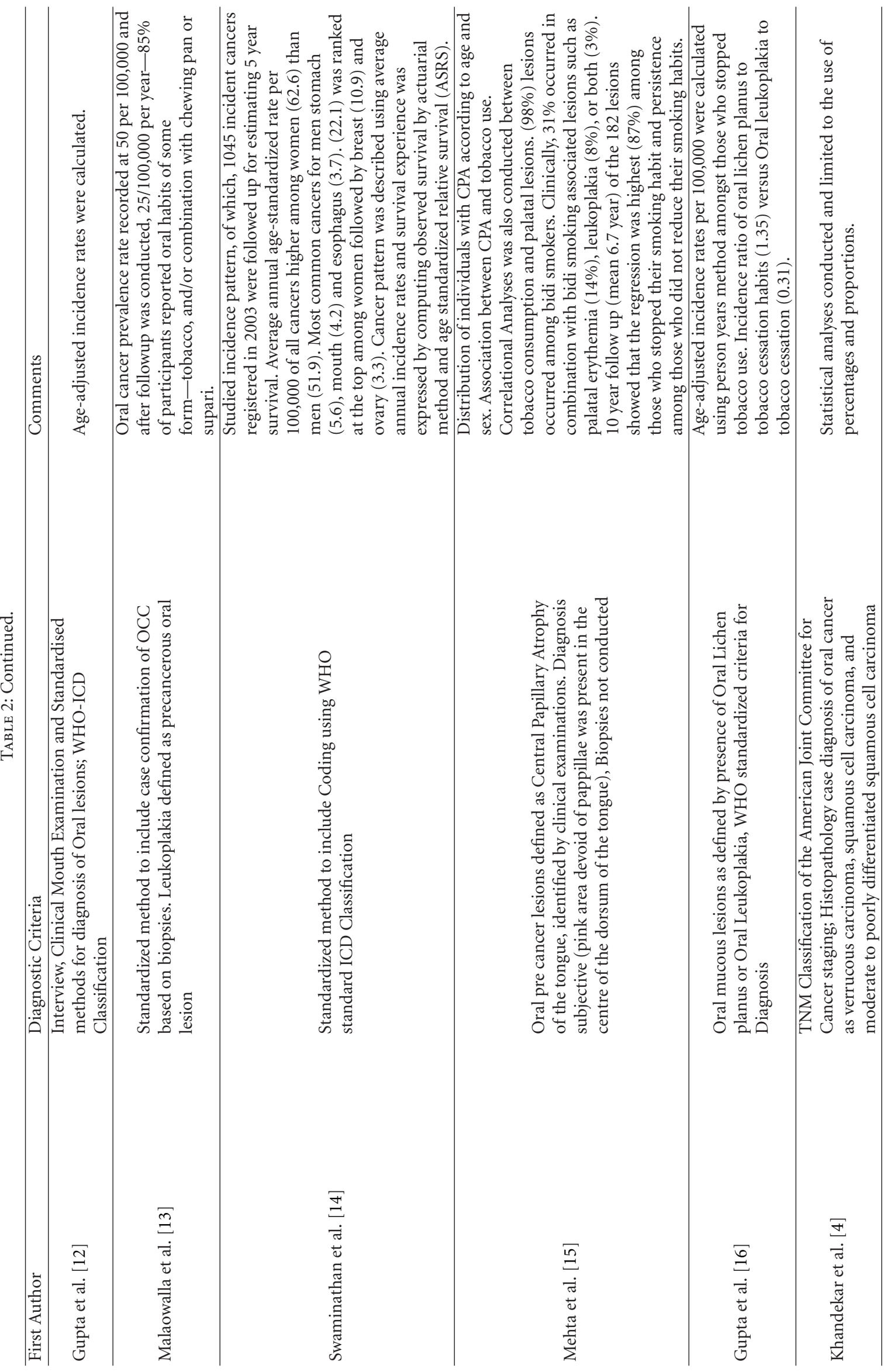




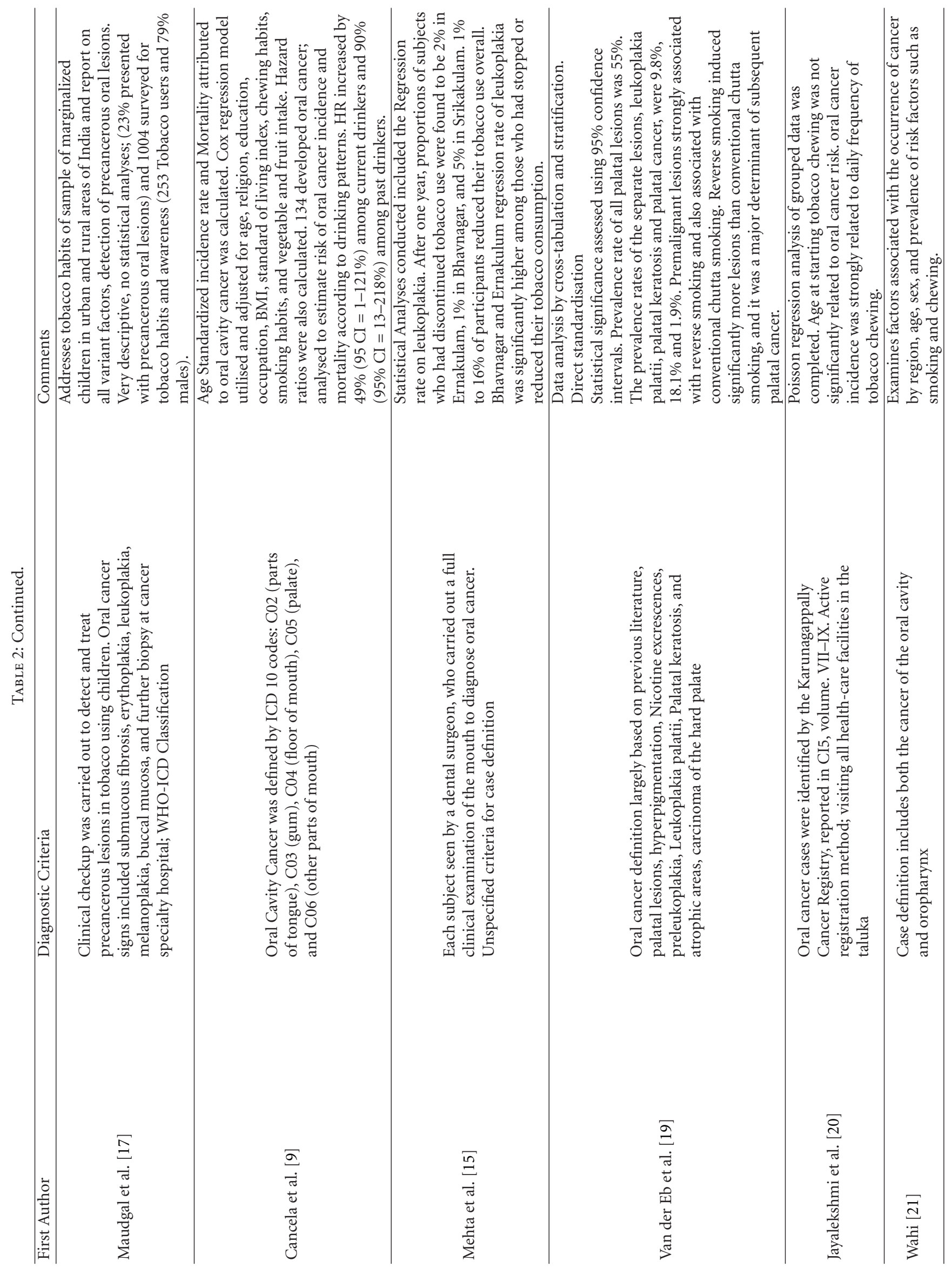


TABLE 3: Age standardized incidence rates per 100,000 population comparison—By location, time period and gender.

\begin{tabular}{lcccc}
\hline Author & Location & Year & M & F \\
\hline CI5 Data, IARC & Mumbai & $1973-1975$ & 16.3 & 10.3 \\
ICMR & Mumbai, Madras, Bangalore & $1982-1984$ & 11 & 10.5 \\
ICMR & Trivandrum (Kerala) & $1982-1984$ & 24.2 & 11.5 \\
Sunny et al. & Mumbai (Maharashtra) & $1986-2000$ & 12.6 & 7.3 \\
Manoharan et al. & Delhi & $2001-2005$ & 11.4 & 3.7 \\
\hline
\end{tabular}

Table 3 summarizes the age-standardised (or adjusted) incidence rates per 100,000 population for oral cancer reported in reviewed literature by location in India and time period under study. Different studies reported a range of age-adjusted incidence rates (per 100,000 population) for oral cancer. A 4 -fold variation in these rates suggests methodological differences in the regional registration of oral cancer. The extent to which multiple sources of case ascertainment resulted in measurement bias is unclear; however, data suggests the occurrence of under reporting or over reporting at different sites.

Manoharan et al. [3] reported variable age-standardised incidence rates across various geographical regions within India for a defined period of time (2004-2005). Data for Kolkata only includes 2005. Variations in case registration technique such as medical record abstraction by trained medical social workers may have contributed to sample selection bias. Additionally, patient interviews were utilized to obtain information highly prone to recall bias, explaining some variation.

As can be seen in Table 3, age-standardised incidence rates when stratified by sex were lower in females than males in the reported articles and data repositories across the different time frames. This is consistent with our earlier comparison in Figure 1. In Figures 2 and 3, variation in age-standardised incidence rates per 100,000 population by location and time period in males is reported in the literature.

As can be seen Figure 4, age-standardised incidence rates were compared across the rural males in selected studies. These rates were identified through the rural populationbased cancer registries. Variation in the data calls into question the robustness of cancer registration information utilized in the methodology of these studies especially in agrarian based rural parts of India where lack of transportation inhibits patients from seeking care.

\section{Cancer Registry Data-Comparisons from IARC Sources}

These IARC projects provide estimates of the incidence of, and mortality from major type of cancers for all countries of the world. GLOBOCAN only includes data for 2008. Data on India was extracted from population-based cancer registries. Figure 5 shows the age-standardised incidence and mortality rates for all types of cancer. Note that oral cancer ranks third amongst all types of cancer.
As can be seen in Figure 6 and consistent with earlier estimates, when stratified by sex, males have a higher agestandardised incidence and mortality rate than females.

The CI5 series compares age-standardised incidence rates in India by time, location and gender and registries summarised in Table 4. Tables 5, 6, 7 describe a comparisonof incidence and trends consistent with earlier findings.

\section{Incidence and Trends of Oral Cancer in India}

Oral cancer is a heterogeneous group of cancers arising from different parts of the oral cavity, with different predisposing factors, prevalence, and treatment outcomes. It is the sixth most common cancer reported globally with an annual incidence of over 300,000 cases, of which $62 \%$ arise in developing countries.

There is a significant difference in the incidence of oral cancer in different regions of the world, with the age-adjusted rates varying from over 20 per 100,000 population in India, to 10 per 100,000 in the U.S.A, and less than 2 per 100,000 in the Middle East [27].

In comparison with the U.S. population, where oral cavity cancer represents only about $3 \%$ of malignancies, it accounts for over $30 \%$ of all cancers in India. The variation in incidence and pattern of oral cancer is due to regional differences in the prevalence of risk factors.

\section{Variability in Incidence}

Age-adjusted incidence of oral cancer is highly variable in India. The population-based cancer registry data, as well as the literature reviewed in our search demonstrate the nationwide incidence can be as high as 20 per 100,000 population, which varied considerably based on study designs, sampling methodology and case ascertainment, as well as by age, gender and location. Variations in age-specific incidence rates also increased with age, which drops at the age of seventy, a trend which is consistent in multiple studies.

Studies reporting active case finding as a mode of ascertainment may only include those individuals registered in different parts of the country. Underregistration may have been magnified in rural areas. As a result, registration rate may not reflect the true incidence in these areas. This may very well be the case in other parts of India.

Although the definition of oral cancer in most studies reviewed was standardised as per the WHO-ICD Classification system, the diagnosis of oral cancer is dependent on the clinical examination conducted by staff or in some 


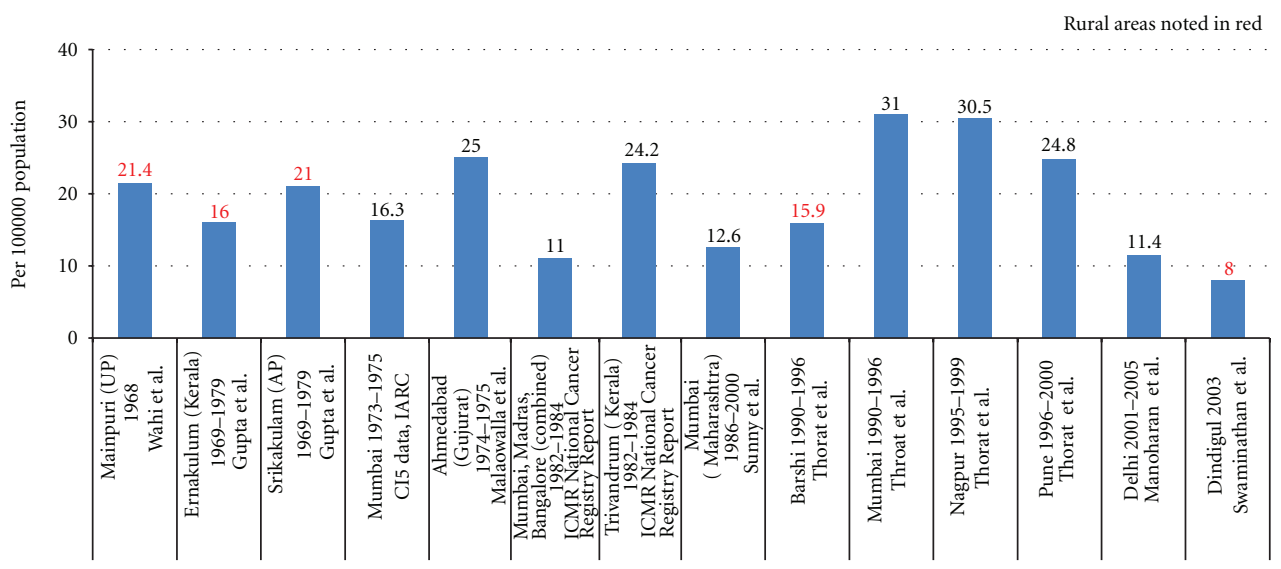

FIGURE 2: Age standardized incidence rates per 100,000 population for oral cancer reported in reviewed literature-by location and time period (in males only).

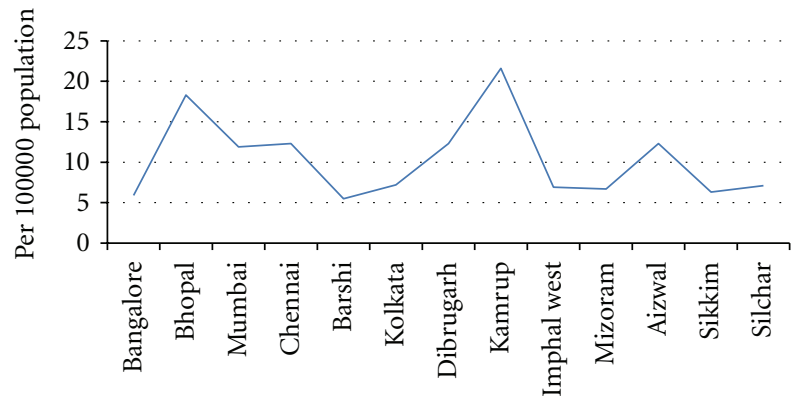

FIGURE 3: Age standardized incidence rates per 100,000 population (in males only). 2004-2005 reported in Manoharan et al. [3].

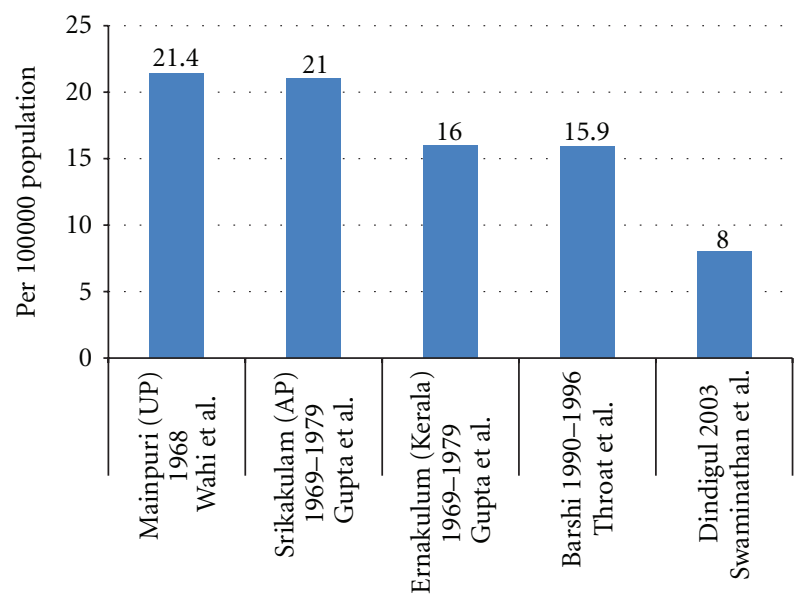

Figure 4: Age standardized incidence rates per 100,000 population comparison-rural males only.

studies the authors themselves. Such examinations are prone to numerous variations based on practice in different parts of the country, resulting in inaccurate coding of data, and unreliable registration information.
In a majority of the studies, data were collected through one-time community or hospital-based cross-sectional surveys; however, no studies refer to continuous available data. Such data would assist in understanding the trends in cancer occurrence and variation according to demographic or life style characteristics of the population to determine further aetiological factors influencing oral cancer.

\section{Aetiological Factors}

High incidence of oral cancer in India can be attributed to a number of aetiological factors. Although not a focus of this paper, the limited studies reported the use of tobacco (smoking or chewing) or alcohol intake associated with oral cancer. Seven studies discussed the associations between use of tobacco and oral cancer incidence. Mehta et al. [15] reported the regression rate of leukoplakia as significantly higher among those who had stopped or reduced tobacco consumption in rural populations in Kerala, Andhra Pradesh and Gujarat. Gupta et al. [12] reported an association between the cessation of tobacco habits and a drop in the incidence of leukoplakia implying reduced risk for oral cancer after cessation of tobacco use. Khandekar et al. [4] reported tobacco consumption habits among subjects that included chewing (in the form of betel quid, or khaini) and smoking (bidis and cigarettes) as the common cause of oral cancer. Based on the TNM classification, $48 \%$ of these oral cancer cases presented in later stages, that is, III and IV. Mehta et al. [15] reported occurrence of CPA of the tongue as a marker for oral precancerous lesions among users of bidis in rural parts of India with $98 \%$ lesions occurring in this group. A ten-year followup showed that regression was the highest amongst those who stopped the smoking habit. Jayalekshmi et al. [20] reported a significant association between oral cancer incidence and daily frequency of tobacco chewing $(P<0.001$, which increased 9.2 fold among women chewing tobacco 10 times or more a day, with the highest risk during the first twenty years of chewing).

One study discussed the association between alcohol use and oral cancer. Cancela et al. [9] reported a significant 


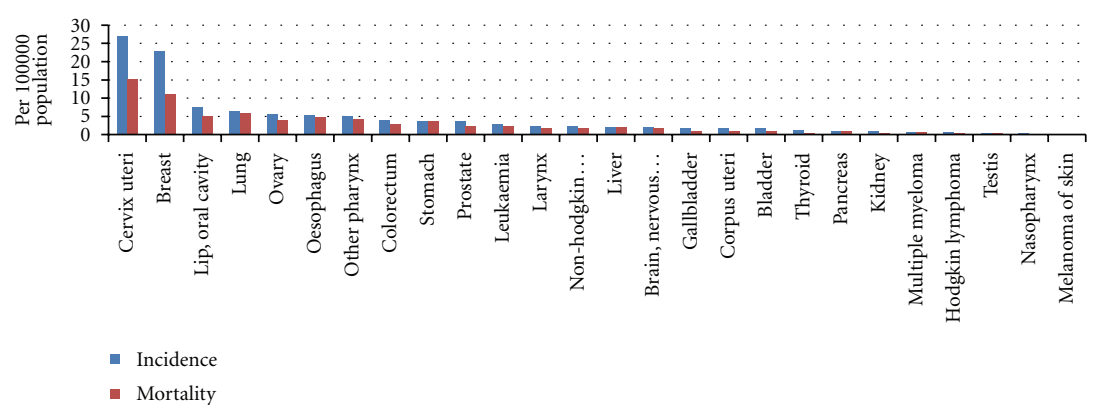

FIGURE 5: Incidence and mortality rates (age standardised) by cancer type in India-(sexes combined) data extracted from Globocan, 2008 data.

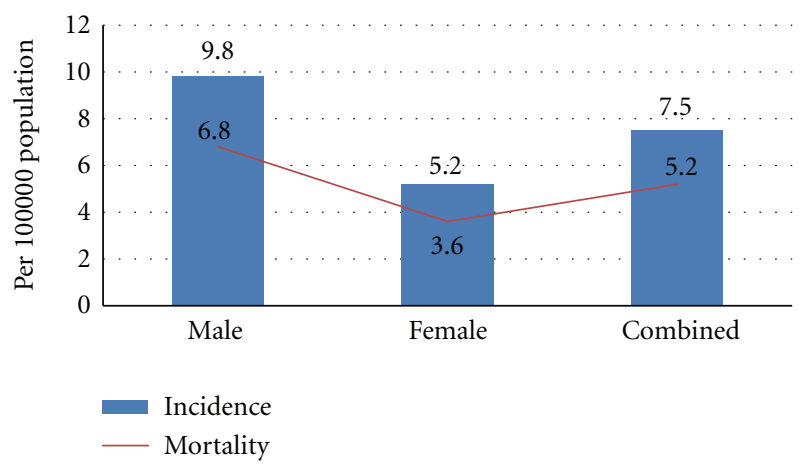

Figure 6: Incidence and mortality rates (age standardized) lip and oral cancer in India-by sex extracted from Globocan, 2008 data.

association between risk between alcohol intake and development of oral cancer in Kerala males among current- and past-drinkers. They quoted an increased hazard ratio (HR) of $49 \%(95 \% \mathrm{CI}=1-121 \%)$ among current drinkers and $90 \%$ (95\% CI $=13-218 \%)$ among past drinkers. A significant dose response relationship between intake frequencies, duration, and risk was observed.

\section{Tobacco Use}

Tobacco use and alcohol are known risk factors for cancers of the oral cavity. Estimates indicate $57 \%$ of all men and $11 \%$ of women between 15-49 years of age use some form of tobacco. Besides smoking, use of smokeless tobacco is also widely prevalent as noted in Box 2, the use of Betel quid, also referred to as pan consist of pieces of areca nut, processed or unprocessed tobacco, aqueous calcium hydroxide (slaked lime), and some spices wrapped in the leaf of piper betel vine leaf. This is very common and is accepted socially and culturally in many parts of India. Additionally, gutka, zarda, kharra, mawa, and khainni are all dry mixtures of lime, areca nut flakes, and powdered tobacco custom mixed by vendors. In recent years, commercially available sachets of premixed areca nut, lime, condiments with or without powdered tobacco have become very popular, particularly among younger Indians. Typically, the pan or gutka is kept in the cheek and chewed or sucked for 10-15 minutes, with some users keeping it in overnight.
Acquisition of the tobacco habit typically occurs early in life through imitation of a family member or peers. Various studies carried out across the country report that at least a third of school students less than 15 years of age have used one form or another of tobacco. However, with improved public health education, the prevalence of these risk factors is decreasing around the globe, including in India [1].

Oral cancer incidence from 1990 to 2005 reveals the benefit of public health interventions such as screening demonstrating potential significant reductions in oral cancer incidence. A comparison of oral cancer incidence in India and USA has shown a similar downward trend in both countries. However, the reduction is much more dramatic in India, where there is a much higher prevalence of oral cancer.

Recently, the trend has also been observed towards increased incidence of oral cancer among young adults. This increase in incidence is observed in patients with tongue cancer. In an analysis of 482 consecutive patients presenting with head and neck cancer to a tertiary care cancer center in India, 135 out of the $286(47 \%)$ oral cavity cancer patients did not have any known risk habits (tobacco or alcohol use, unpublished data from a blog).

\section{Global Burden of Disease}

Approximately $12 \%$ of deaths worldwide occur due to cancer, and in about twenty years, it is projected to increase from about 6 to 10 million [26].

In the USA, cancer incidence and associated mortality have declined due to improved infrastructure of the health systems that include improved health education and awareness translating to improved prevention, earlier detection and availability of treatment options [28].

However, even though cancer has been previously thought to be a disease of the western world, more than half of all cancers occur in developing and under-developed countries becoming one of the leading causes of death and disability [29]. Consequently, cancer control is quickly becoming a global health priority. In 2009, global health and cancer care community leaders formed a global task force focused on the expansion of access to cancer care and control in developing countries and with a charter to propose, implement, and evaluate strategies to reduce the global burden of disease attributed to cancer [30]. 
TABLE 4: Summary of Indian cancer registries reported by IARC, CI5 Series.

\begin{tabular}{|c|c|c|c|}
\hline \multicolumn{4}{|c|}{ CI5 I-IX registries } \\
\hline \multirow{2}{*}{$\frac{\text { Registry/population }}{\text { India, Mumbai (Bombay) }}$} & \multirow{2}{*}{$\frac{\text { Volume }}{2}$} & \multicolumn{2}{|c|}{ Time period } \\
\hline & & 1964 & 1966 \\
\hline India, Mumbai (Bombay) & 3 & 1968 & 1972 \\
\hline India, Mumbai (Bombay) & 4 & 1973 & 1975 \\
\hline India, Poona & 4 & 1973 & 1977 \\
\hline India, Bangalore & 5 & 1982 & 1982 \\
\hline India, Chennai (Madras) & 5 & 1982 & 1982 \\
\hline India, Mumbai (Bombay) & 5 & 1978 & 1982 \\
\hline India, Nagpur & 5 & 1980 & 1982 \\
\hline India, Poona & 5 & 1978 & 1982 \\
\hline India, Ahmedabad & 6 & 1983 & 1987 \\
\hline India, Bangalore & 6 & 1983 & 1987 \\
\hline India, Chennai (Madras) & 6 & 1983 & 1987 \\
\hline India, Mumbai (Bombay) & 6 & 1983 & 1987 \\
\hline India, Bangalore & 7 & 1988 & 1992 \\
\hline India, Barshi & 7 & 1988 & 1992 \\
\hline India, Chennai (Madras) & 7 & 1988 & 1992 \\
\hline India, Karunagappally & 7 & 1991 & 1992 \\
\hline India, Mumbai (Bombay) & 7 & 1988 & 1992 \\
\hline India, Trivandrum & 7 & 1991 & 1992 \\
\hline India, Ahmedabad & 8 & 1993 & 1997 \\
\hline India, Bangalore & 8 & 1993 & 1997 \\
\hline India, Chennai (Madras) & 8 & 1993 & 1997 \\
\hline India, Delhi & 8 & 1993 & 1996 \\
\hline India, Karunagappally & 8 & 1993 & 1997 \\
\hline India, Mumbai (Bombay) & 8 & 1993 & 1997 \\
\hline India, Nagpur & 8 & 1993 & 1997 \\
\hline India, Poona & 8 & 1993 & 1997 \\
\hline India, Trivandrum & 8 & 1993 & 1997 \\
\hline India, Chennai (Madras) & 9 & 1998 & 2002 \\
\hline India, Delhi & 9 & 1998 & 2002 \\
\hline India, Karunagappally & 9 & 1998 & 2002 \\
\hline India, Mumbai (Bombay) & 9 & 1998 & 2002 \\
\hline India, Nagpur & 9 & 1998 & 2002 \\
\hline India, Poona & 9 & 1998 & 2002 \\
\hline India, Trivandrum & 9 & 1998 & 2002 \\
\hline
\end{tabular}

\section{Limitations}

This review does not come without limitations. Firstly, a number of studies may not have been found using the identified search strategy. Secondly, mortality and survival from oral cancer in India have not been described and criteria used to identify studies may have resulted in published studies only where results are known to be significant or where incidence rates are high. As a result, bias from not including mortality and survival and publication bias may lead to overestimating the true incidence. Finally, the search strategy was also limited to studies published in English, leaving out local language-based Indian journals.

\section{Projections}

Cancer is not uncommon in India, where the number of people living with the disease is estimated to be around 2.5 million, with over 0.8 million new cases and 0.55 million deaths occurring each year [31]. According to the International Agency for Research on cancer (IARC), a group chartered by the World Health Organization to conduct research and develop scientific strategies for cancer prevention and control; cancers of the oral cavity, lungs, oesophagus, stomach, cervix, and breast are some of the most commonly occurring forms in both the male and female population of India. 
TABLe 5: Age standardized incidence rate-1993 to 1997.

\begin{tabular}{lcc}
\hline Oral cavity and pharynx cancer & \multicolumn{2}{c}{ Age groups $0-85+$} \\
Location in India & Male & Female \\
\hline India, Ahmedabad & 29.6 & 7.5 \\
India, Bangalore & 15.2 & 11.2 \\
India, Chennai (Madras) & 21.9 & 10.4 \\
India, Delhi & $18^{*}$ & $6.4^{*}$ \\
India, Karunagappally & 16.4 & 6.4 \\
India, Mumbai (Bombay) & 22.5 & 10 \\
India, Nagpur & 23.4 & 8.2 \\
India, Poona & 19.3 & 9.4 \\
India, Trivandrum & 21.4 & 9.1 \\
\hline
\end{tabular}

* Includes data only upto 1996. See [24].

TABLE 6: Age standardized incidence rates-1998 to 2002.

\begin{tabular}{lcc}
\hline Oral cavity and pharynx cancer & \multicolumn{2}{c}{ Age Groups 0-85+ } \\
Location in India & Male & Female \\
\hline India, Chennai (Madras) & 20.8 & 10 \\
India, Delhi & 17 & 5.6 \\
India, Karunagappally & 20.4 & 8.9 \\
India, Mumbai (Bombay) & 19 & 8 \\
India, Nagpur & 19 & 7.5 \\
India, Poona & 15.6 & 9.5 \\
India, Trivandrum & 21.6 & 7.9 \\
\hline
\end{tabular}

See [25].

Oral cancer in particular will continue to be a major problem. In Figure 7, crude incidence projections by Globocan demonstrate that oral cancer crude incidence will increase in India by 2020 and 2030 in both sexes.

Variability in the age-adjusted incidence rates of oral cancer in different regions of India has increased over the years. Although this review does not provide substantial evidence or information on aetiological factors such as smoking or chewing tobacco and the use of alcohol which increases ones risk of developing oral cancer, the specific focus on these factors will provide opportunities for future research aimed at prevention and control of the disease.

\section{Screening and Early Detection}

Despite the fact that the oral cavity is accessible for visual examination, and that oral cancers and premalignant lesions have well-defined clinical diagnostic features, oral cancers are typically detected in their advanced stages. In fact, in India, $60-80 \%$ of patients present with advanced disease as compared to $40 \%$ in developed countries. Consistent with patients presenting for medical care with more advanced disease in India compared with developed countries, overall survival is also reduced. Early detection would not only improve the cure rate, but it would also lower the cost and morbidity associated with treatment.

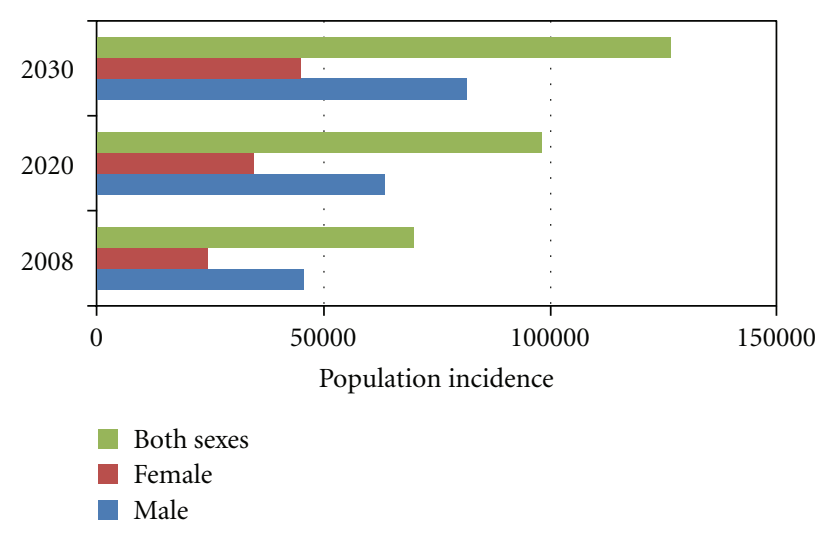

Figure 7: Crude incidence projections for lip/oral cavity cancer (2008 to 2030). Data extracted from Globocan, 2008 data. Population forecasts were extracted from the United Nations, World Population prospects, the 2008 revision. Numbers are computed using age-specific rates and corresponding populations for 10 agegroups.

It is imperative that cost-effective oral cancer screening and awareness initiatives be introduced in high-risk populations such as those found in India. Several large populationbased oral cancer screening programs have been carried out, either as opportunistic screenings or as population-wide screenings. Although these studies have confirmed the effectiveness of screening to detect oral cancer and precancerous lesions, only recently has a study from India demonstrated that oral cancer screening by trained health workers can lower mortality of the disease-especially in individuals with a history of tobacco use [32]. In this randomised, controlled trial of almost 192,000 people, carried out over an eight-year period, there was a significant reduction in mortality in the intervention arm (29.9 cases per 100,000) versus the control arm (45.4 cases per 100,000), due to detection of oral cancer at an early stage.

A cost-effectiveness analysis revealed that an oral cancer visual inspection by trained health workers can be carried out for under U.S. $\$ 6$ per person. The incremental cost per life-year saved was U.S. $\$ 835$ for the all-screened population and U.S. $\$ 156$ in the high-risk population (individuals with a tobacco habit) [33].

Mouth self-examination could further reduce the cost of the screening and increase awareness in high-risk communities in India. Such a simple and cost-effective strategy has the potential to have a significant impact on the awareness of oral cancer in the broader community.

\section{Future Challenges}

Despite the fact that oral cancer and consequences can be prevented, treated, and controlled, there exists a significant gap in the Indian public's knowledge, attitudes, and behaviours. Efforts must be made to introduce a suite of preventive measures that has the potential to significantly reduce the burden and to help bridge the gap between research, development and public awareness. Knowledge 
TABLE 7: Comparison of age standardized incidence rates per 100,000 by time, location and gender.

\begin{tabular}{lcccc}
\hline & & Males & & \multicolumn{2}{c}{ Females } \\
& $1998-2002$ & $1993-1997$ & $1998-2002$ & $1993-1997$ \\
\hline Chennai (Madras) & 20.8 & 21.9 & 10 & 10.4 \\
Delhi & 17 & $\mathbf{1 8}$ & 5.6 & $\mathbf{6 . 4}$ \\
Karunagappally & 20.4 & 16.4 & 8.9 & 6.4 \\
Mumbai (Bombay) & 19 & 22.5 & 8 & 10 \\
Nagpur & 19 & 23.4 & 7.5 & 8.2 \\
Poona & 15.6 & 19.3 & 9.5 & 9.4 \\
Trivandrum & 21.6 & 21.4 & 7.9 & 9.1 \\
\hline
\end{tabular}

Bold data only include rates upto 1996.

See [25].

betel quid (or pan quid) — prepared by wrapping cured, dried tobacco leaves or stems and slices of dried or fresh areca nut in a fresh green betel leaf, smeared with a paste calcium hydroxide. In some parts of India, condiments or flavouring agents or sweeteners are added to it bidi (also referred to as chutta) is a form of Indian cigarette used in rural areas and prepared by rolling small quantity of tobacco in a dried leaf.

Box 2: Definition of tobacco products as reported in peer-reviewed literature.

dissemination to help people adopt behaviour patterns to improve their health and decisions making process and to provide required public health education and training to promote lifestyle modifications are key to confronting the challenge.

The greatest threat of the oral cancer burden exists among the lower socioeconomic strata. This segment of the population is the most vulnerable because of higher exposure to the risk factor-tobacco-which complicates the situation further. They have the most limited access to education, prevention and treatment. These disparities should be addressed to push for provision of easy, accessible, detection, and treatment services. Prevention through action against risk factors, especially tobacco will be key to reducing the burden amongst these groups.

\section{Abbreviations}

$\begin{array}{ll}\text { AP: } & \text { Andhra Pradesh } \\ \text { ASRS: } & \text { Age-standardised relative survival } \\ \text { ASR: } & \text { Age-standardised rate } \\ \text { CI5: } & \text { Cancer incidence in } 5 \text { continents } \\ \text { CPA: } & \text { Central papillary atrophy } \\ \text { DACR: } & \text { Dindigul Ambilikkai cancer registry } \\ \text { GLOBOCAN: } & \text { IARC Global Cancer Project } \\ \text { HW: } & \text { Health workers } \\ \text { HR: } & \text { Hazard ratio } \\ \text { IARC: } & \text { International Agency for Research on } \\ & \text { Cancer } \\ \text { ICMR: } & \text { Indian Council of Medical Research } \\ \text { ICD: } & \text { International Classification of Diseases } \\ \text { MeSH: } & \text { Medical subject headings } \\ \text { NGO: } & \text { Nongovernmental organisation }\end{array}$

OCC: Oral cavity cancer

TNM: Tumour node metastasis

UP: Uttar Pradesh

USA: United States of America

WHO: World Health Organisation.

\section{Acknowledgments}

Author would like to acknowledge Professor Martin Roland, Professor of Health Services Research and Dr. John Powles from the Department of Public Health and Primary Care at the University of Cambridge for mentorship and support, Dr. Rohan D'Souza, Specialist Registrar at Epsom and St. Helier Hospitals NHS Trust, London, United Kingdom, and Dr. Hermann Brenner, German Cancer Research Center, Heidelberg, Germany for comments during the review process. The author also declares that there are no potential conflict of interests, including financial interests, relationships, and affiliation relevant to the subject of the manuscript in any way. No funding was sought in the creation of this work.

\section{References}

[1] J. K. Elango, P. Gangadharan, S. Sumithra, and M. A. Kuriakose, "Trends of head and neck cancers in urban and rural India," Asian Pacific Journal of Cancer Prevention, vol. 7, no. 1, pp. 108-112, 2006.

[2] R. Sankaranarayanan, K. Ramadas, G. Thomas et al., "Effect of screening on oral cancer mortality in Kerala, India: a clusterrandomised controlled trial," The Lancet, vol. 365, no. 9475, pp. 1927-1933, 2005.

[3] N. Manoharan, B. B. Tyagi, and V. Raina, "Cancer incidences in rural Delhi-2004-05," Asian Pacific Journal of Cancer Prevention, vol. 11, no. 1, pp. 73-78, 2010. 
[4] P. S. Khandekar, P. S. Bagdey, and R. R. Tiwari, "oral cancer and Some epidemiological factors: a hospital based study," Indian Journal of Community Medicine, vol. 31, no. 3, pp. 157$159,2006$.

[5] S. Kumar, R. F. Heller, U. Pandey, V. Tewari, N. Bala, and K. T. H. Oanh, "Delay in presentation of oral cancer: a multifactor analytical study," National Medical Journal of India, vol. 14, no. 1, pp. 13-17, 2001.

[6] Fritz et al., International Classification of Diseases For Oncology, World Health Organization, Geneva, Switzerland, 3rd edition, 2000.

[7] D. I. Conway, M. Petticrew, H. Marlborough, J. Berthiller, M. Hashibe, and L. M. D. Macpherson, "Socioeconomic inequalities and oral cancer risk: a systematic review and meta-analysis of case-control studies," International Journal of Cancer, vol. 122, no. 12, pp. 2811-2819, 2008.

[8] V. L. Allgar and R. D. Neal, "Sociodemographic factors and delays in the diagnosis of six cancers: analysis of data from the 'National Survey of NHS Patients: cancer,', The British Journal of Cancer, vol. 92, no. 11, pp. 1971-1975, 2005.

[9] M. D. C. Cancela, K. Ramadas, J. M. Fayette et al., "Alcohol intake and oral cavity cancer risk among men in a prospective study in Kerala, India," Community Dentistry and Oral Epidemiology, vol. 37, no. 4, pp. 342-349, 2009.

[10] L. Sunny, B. B. Yeole, M. Hakama et al., "Oral cancers in Mumbai, India: a fifteen years perspective with respect to incidence trend and cumulative risk," Asian Pacific Journal of Cancer Prevention, vol. 5, no. 3, pp. 294-300, 2004.

[11] R. V. Thorat, N. S. Panse, A. M. Budukh, K. A. Dinshaw, B. M. Nene, and K. Jayant, "Prevalence of tobacco use and tobaccodependent cancers in males in the Rural Cancer Registry population at Barshi, India," Asian Pacific Journal of Cancer Prevention, vol. 10, no. 6, pp. 1167-1170, 2009.

[12] P. C. Gupta, F. S. Mehta, and J. J. Pindborg, "Intervention study for primary prevention of oral cancer among 36,000 Indian tobacco users," The Lancet, vol. 1, no. 8492, pp. 1235-1238, 1986.

[13] A. M. Malaowalla, S. Silverman, and N. J. Mani, "Oral cancer in 57,518 industrial workers in Gujarat, India. A prevalence and followup study," Cancer, vol. 37, no. 4, pp. 1882-1886, 1976.

[14] R. Swaminathan, R. Selvakumaran, P. O. Esmy et al., "Cancer pattern and survival in a rural district in South India," Cancer Epidemiology, vol. 33, no. 5, pp. 325-331, 2009.

[15] F. S. Mehta, R. B. Bhonsle, P. R. Murti, D. K. Daftary, P. C. Gupta, and J. J. Pindborg, "Central papillary atrophy of the tongue among bidi smokers in India: a 10-year study of 182 lesions," Journal of Oral Pathology and Medicine, vol. 18, no. 8, pp. 475-480, 1989.

[16] P. C. Gupta, P. R. Murti, R. B. Bhonsle, F. S. Mehta, and J. J. Pindborg, "Effect of cessation of tobacco use on the incidence of oral mucosal lesions in a 10-yr follow-up study of 12,212 users," Oral diseases, vol. 1, no. 1, pp. 54-58, 1995.

[17] S. Maudgal, N. More, and S. Raval, "Study on tobacco use and awareness among marginalized children," Indian journal of cancer, vol. 47, pp. 14-18, 2010.

[18] F. S. Mehta, M. B. Gupta, and J. J. Pindborg, "An intervention study of oral cancer and precancer in rural Indian populations: a preliminary report," Bulletin of the World Health Organization, vol. 60, no. 3, pp. 441-446, 1982.

[19] M. M. Van der Eb, E. M. S. Leyten, S. Gavarasana, J. P. Vandenbroucke, P. Meera Kahn, and F. J. Cleton, "Reverse smoking as a risk factor for palatal cancer: a cross-sectional study in rural Andhra Pradesh, India," International Journal of Cancer, vol. 54, no. 5, pp. 754-758, 1993.

[20] P. A. Jayalekshmi, P. Gangadharan, S. Akiba, R. R. K. Nair, M. Tsuji, and B. Rajan, "Tobacco chewing and female oral cavity cancer risk in Karunagappally cohort, India," The British Journal of Cancer, vol. 100, no. 5, pp. 848-852, 2009.

[21] P. N. Wahi, "The epidemiology of oral anc oropharyngeal cancer. A report of the study in Mainpuri district, Uttar Pradesh, India," Bulletin of the World Health Organization, vol. 38, no. 4, pp. 495-521, 1968.

[22] R. Sankaranarayanan, K. Ramadas, G. Thomas et al., "Effect of screening on oral cancer mortality in Kerala, India: a clusterrandomised controlled trial," The Lancet, vol. 365, no. 9475, pp. 1927-1933, 2005.

[23] P. C. Gupta, F. S. Mehta, J. J. Pindborg et al., "A primary prevention study of oral cancer among Indian villagers. Eightyear follow-up results," IARC scientific publications, no. 103, pp. 149-156, 1990.

[24] D. M. Parkin, S. L. Whelan, J. Ferlay, L. Teppo, and D. B. Thomas, Eds., Cancer Incidence in Five Continents, vol. 8 of IARC Scientific Publications no 155, IARC, Lyon, France, 2002.

[25] M. P. Curado, B. Edwards, H. R. Shin et al., Eds., Cancer Incidence in Five Continents, vol. 9 of IARC Scientific Publications no 160, IARC, Lyon, France, 2007.

[26] J. Ferlay, H. R. Shin, F. Bray, D. Forman, C. Mathers, and D. M. Parkin, "GLOBOCAN, 2003, 2008, 2010 cancer Incidence and Mortality Worldwide," IARC CancerBase 10.

[27] R. Sankaranarayanan, E. Masuyer, R. Swaminathan, J. Ferlay, and S. Whelan, "Head and neck cancer: a global perspective on epidemiology and prognosis," Anticancer Research, vol. 18, no. 6 B, pp. 4779-4786, 1998.

[28] A. Jemal, M. J. Thun, L. A. G. Ries et al., "Annual report to the nation on the status of cancer, 1975-2005, featuring trends in lung cancer, tobacco use, and tobacco control," Journal of the National Cancer Institute, vol. 100, no. 23, pp. 1672-1694, 2008.

[29] F. Sloan et al., Cancer Control Opportunities in Low and Middle Income Countries, Institute of Medicine of the National Academies, National Academies Press, Washington, DC, USA, 2007.

[30] P. Farmer, J. Frenk, F. M. Knaul et al., "Expansion of cancer care and control in countries of low and middle income: a call to action," The Lancet, vol. 376, no. 9747, pp. 1186-1193, 2010.

[31] A. Nandakumar, P. C. Gupta, P. Gangadharan, R. N. Visweswara, and D. M. Parkin, "Geographic pathology revisited: development of an atlas of cancer in India," International Journal of Cancer, vol. 116, no. 5, pp. 740-754, 2005.

[32] D. K. Daftary, "Temporal role of tobacco in oral carcinogenesis: a hypothesis for the need to prioritize on precancer," Indian journal of cancer, vol. 47, supplement 1, pp. 105-107, 2010.

[33] S. Subramanian, R. Sankaranarayanan, B. Bapat et al., "Costeffectiveness of oral cancer screening: results from a cluster randomized controlled trial in India," Bulletin of the World Health Organization, vol. 87, no. 3, pp. 200-206, 2009. 


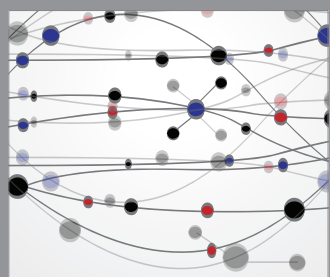

The Scientific World Journal
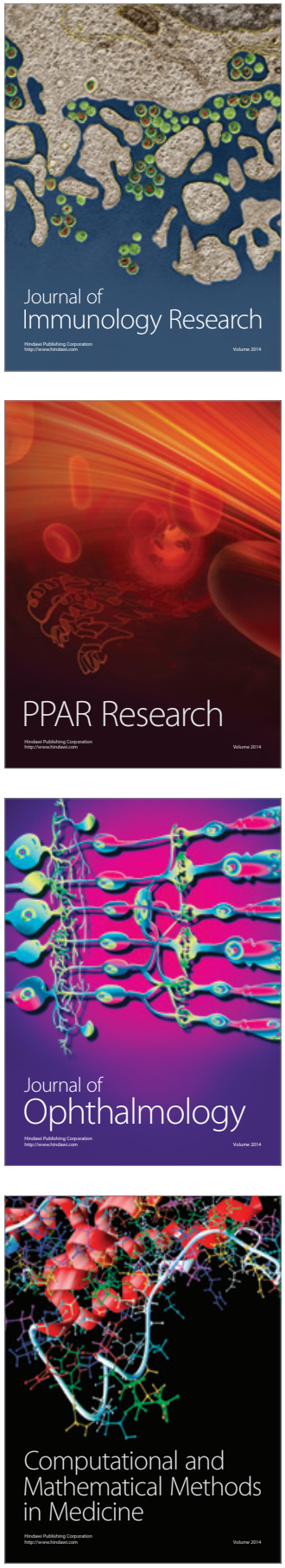

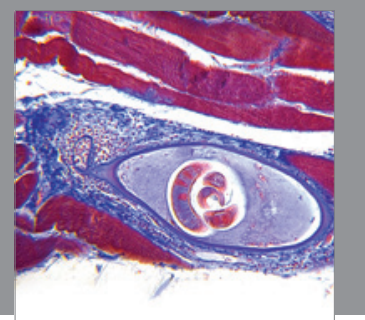

Gastroenterology

Research and Practice
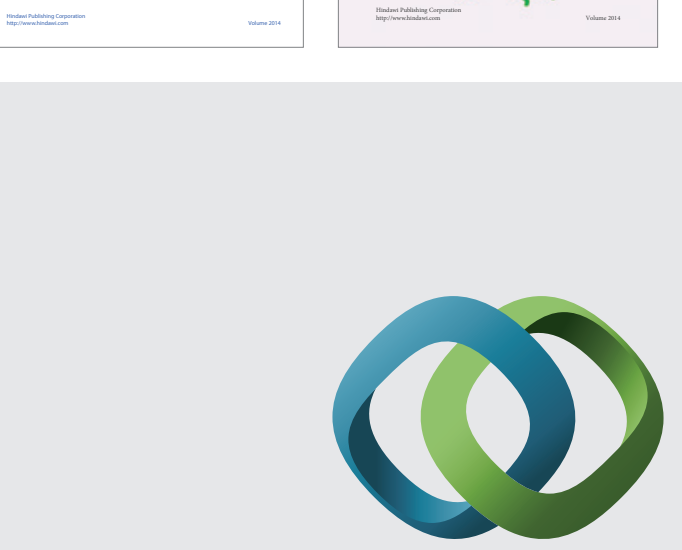

\section{Hindawi}

Submit your manuscripts at

http://www.hindawi.com
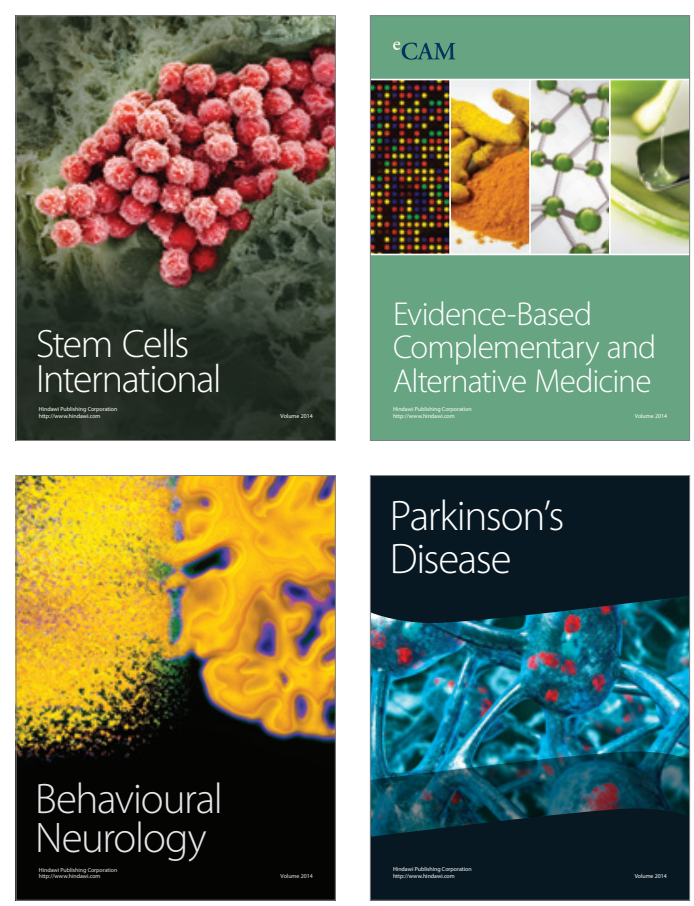

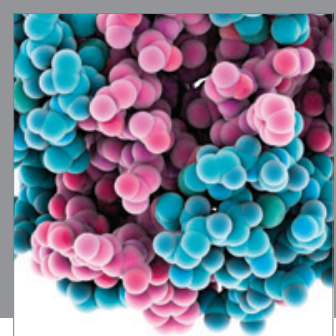

Journal of
Diabetes Research

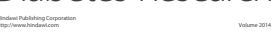

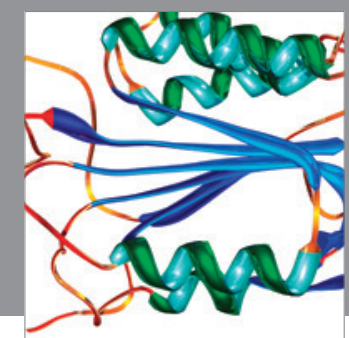

Disease Markers
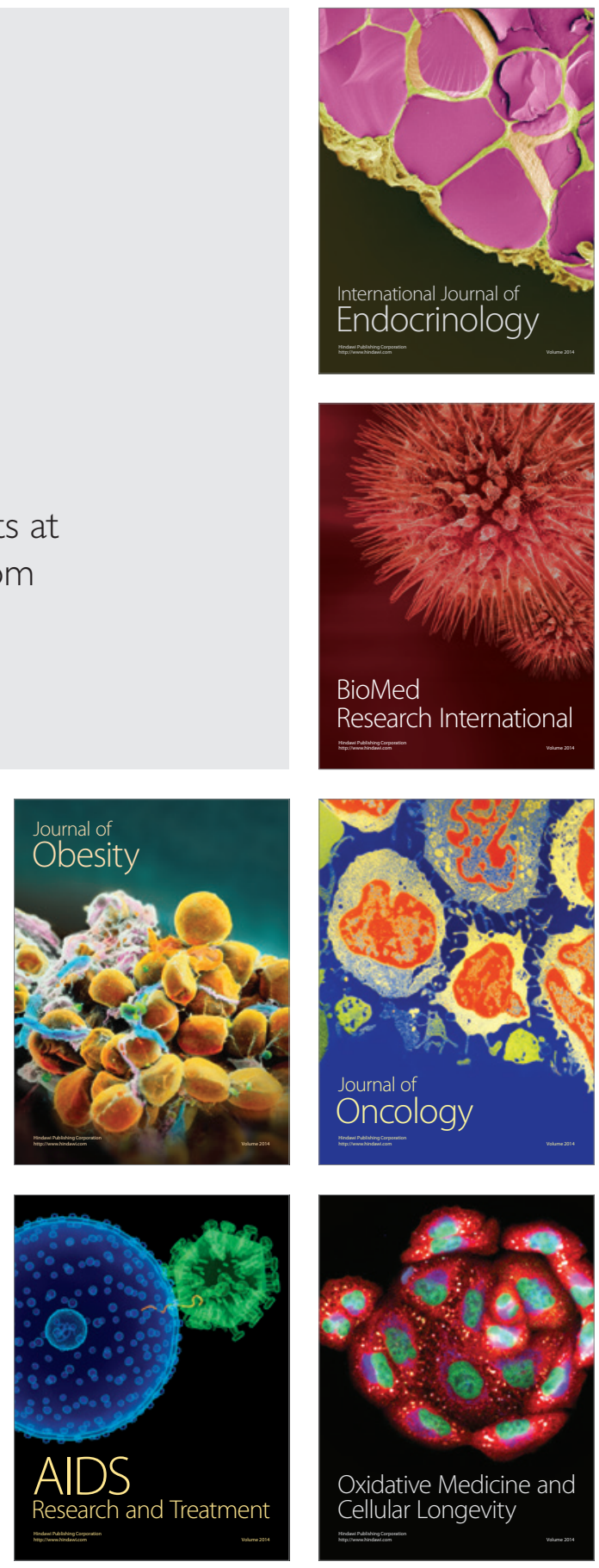